\title{
Investigation of European tungsten materials exposed to high heat flux $\mathrm{H} / \mathrm{He}$ neutral beams
}

\author{
H. Greuner ${ }^{1 *}$, H. Maier ${ }^{1}$, M. Balden ${ }^{1}$, Ch. Linsmeier ${ }^{1}$, B. Böswirth ${ }^{1}$, S. Lindig ${ }^{1}$, P. Norajitra ${ }^{2}$, \\ S. Antusch ${ }^{2}$ and M. Rieth ${ }^{2}$ \\ ${ }^{1}$ Max-Planck-Institut für Plasmaphysik, EURATOM Association, 85741 Garching, Germany \\ ${ }^{2}$ Karlsruhe Institute of Technology, Institute for Applied Materials, P.O. Box 3640, 76021, \\ Karlsruhe, Germany
}

\begin{abstract}
Tungsten is being considered as a potential plasma-facing material for future fusion devices, primarily due to its low erosion rate and high heat resistance. The intrinsic problem of this material, the brittleness even at elevated temperatures, requires the development and assessment of new tungsten materials.

In the frame of the European material development programme for future fusion power plants $\mathrm{W}$ containing 5 wt.\% Ta as well as uniaxially forged ultra-high purity $\mathrm{W}$ and powder injection moulded $\mathrm{W}$ were assessed in a neutral beam high heat flux test facility at IPP Garching.

The investigation of the morphology modification of tungsten, occurring during heat loading using $\mathrm{H}$ and $\mathrm{He}$ particles, which simulates the expected divertor operation conditions, is indispensable in order to develop reliable plasma-facing materials. The effects seen, erosion, gas retention and cavity formation, depend on both the loading conditions and the operating temperature.

This contribution presents a comparative study of the surface morphology changes of different $\mathrm{W}$ materials under hydrogen and helium beam loading to surface temperatures between $1500^{\circ} \mathrm{C}(1773 \mathrm{~K})$ and $2000^{\circ} \mathrm{C}(2273$ $\mathrm{K}$ ), using actively cooled mock-ups. Loading is performed with pure $\mathrm{H}$ and mixed $94 \% \mathrm{H} / 6 \% \mathrm{He}$ beams $(\phi=4 \times$ $10^{21} \mathrm{~m}^{-2} \mathrm{~s}^{-1}$ ), resulting in $10 \mathrm{MW} \mathrm{m} \mathrm{m}^{-2}$ thermal load. Pulse durations of $30 \mathrm{~s}$ are applied to achieve fluences up to $3 \times 10^{25} \mathrm{~m}^{-2}$ under stationary temperature conditions.
\end{abstract}

Keywords: Tungsten, helium, hydrogen, high heat flux, DEMO, divertor, plasma facing components

\section{Introduction}

In current fusion reactor design studies such as the European Power Plant Concept Studies, tungsten is considered to be the most promising material for armour as well as for some structural material applications. This is due to favourable properties such as its low yield for physical sputtering by hydrogen isotopes and its high-temperature strength. Tungsten does, however, also suffer from some material problems. One of its intrinsic problems is the brittleness even at higher temperatures and especially after recrystallization. This, for instance, requires material development activities to improve the ductility. Furthermore, the 
investigation of the surface morphology modification of $\mathrm{W}$, occurring during high heat flux (HHF) loading using $\mathrm{H}$ and $\mathrm{He}$ particles, which simulates the expected operation conditions of fusion devices, is indispensable in order to develop reliable plasma-facing materials (PFMs) for long-term operation. Effects of surface erosion, gas retention, and cavity formation depend on both the loading conditions and the operating temperature.

In the frame of the European material development programme for fusion power plants beyond ITER, a number of differently manufactured W and W alloys are assessed in the Garching Large DIvertor Sample test facility (GLADIS) at $10 \mathrm{MW} \mathrm{m}^{-2}$ cyclic heat load. GLADIS uses neutral beams to generate the HHF loading. Pulse durations of $30 \mathrm{~s}$ were applied on actively water-cooled samples to achieve particle fluences of up to $3 \times 10^{25} \mathrm{~m}^{-2}$ under stationary temperature conditions.

Differently manufactured powder-metallurgy $\mathrm{W}$ grades from Plansee SE, as well as samples produced by powder injection moulding (PIM) were investigated. The materials are investigated in the frame of the European Fusion Development Agreement (EFDA) Topical Group on Materials. Detailed descriptions of these materials can be found, for example, in [1]. The concept of the European He-cooled modular divertor with jet cooling (HEMJ) is based on a nominal steady-state heat load of $10 \mathrm{MW} \mathrm{m}^{-2}$, resulting in a W surface temperature of about $1700^{\circ} \mathrm{C}(1973 \mathrm{~K})$ [2]. Temperature excursions up to $2500^{\circ} \mathrm{C}(2773 \mathrm{~K})$ are allowed for transient plasma events, i.e. edge localized modes (ELMs) [3].

The paper discusses the surface morphology changes of the above mentioned materials under $\mathrm{H}$ and $\mathrm{He}$ beam loading to surface temperatures between $1500^{\circ} \mathrm{C}(1773 \mathrm{~K})$ and $2000^{\circ} \mathrm{C}(2273 \mathrm{~K})$, as well as the bulk material modification due to recrystallization after the long pulse and high temperature loading. To study the influence of particle bombardment in a fusion divertor with a He fraction of 5-10 \%, loading experiments with a mixed 94 at.\% $\mathrm{H}$ and 6at.\% He $(94 \mathrm{H} / 6 \mathrm{He})$ beam were performed. Experimental results of a comparative pure He loading on $\mathrm{W}$ materials were already published earlier [4].

\section{Experimental}

\subsection{Investigated samples}

An overview of the tested $\mathrm{W}$ materials and their manufacturing details is given in Table 1. Sets of eight samples of different $\mathrm{W}$ materials were brazed onto $\mathrm{CuCrZr}$ cooling structures with an inner water-cooling channel of $10 \mathrm{~mm}$ diameter to build the mock-ups. Except for the PIM samples, all samples have been manufactured with a cross-section of $5 \times 10 \mathrm{~mm}^{2}$. The final surface machining was done by mechanical polishing. Two different sample heights of $15 \mathrm{~mm}$ and $20 \mathrm{~mm}$ result in surface temperatures of $1500^{\circ} \mathrm{C}$ $(1773 \mathrm{~K})$ and $2000^{\circ} \mathrm{C}(2273 \mathrm{~K})$ during $10 \mathrm{MW} \mathrm{m}^{-2}$ loading.

The $5 \times 9 \mathrm{~mm}^{2}$ and $15 \mathrm{~mm}$ high PIM samples, manufactured by Karlsruhe Institute of Technology (KIT) [5], were brazed onto a cooling structure made of Ti-Zr-Mo alloy (TZM). The design of the PIM mock-up was adapted to achieve a surface temperature of about $1700^{\circ} \mathrm{C}(1973 \mathrm{~K})$ for $10 \mathrm{MW} \mathrm{m}^{-2}$ loading. The PIM process to produce such samples begins with compounding the moulding mass, the so-called feedstock that consists of about $50-52$ vol\% polymer binder and a binary $\mathrm{W}$ powder mixture of two particle 
sizes of $1.7 \mu \mathrm{m}$ and $0.7 \mu \mathrm{m}$ Fisher Sub-Sieve Size at a ratio of 50:50 (Table 2). To shape the so-called green parts, the feedstock is injected into a closed tool with a cavity that consists of feeder and runner systems and moulds having the inverse shape of the green parts. After this thermoplastic shaping process, the green parts are released from binders and become the so-called brown parts, which are then sintered to dense products at about $1650^{\circ} \mathrm{C}(1923 \mathrm{~K})$ for $\mathrm{W}$. The sintering is followed by hot isostatic pressing to improve the compaction of the microstructure of the material, resulting in a final density of up to $98 \%$ of the theoretical density.

\begin{tabular}{|c|c|c|c|c|}
\hline Sample & Description & Process & Composition & Machining \\
\hline W-PL & commercial & sintering & $>99.97 \%$ & hammering \\
\hline WTa5 & commercial & sintering & W $5 \% \mathrm{Ta}$ & uniaxial forging \\
\hline W-UHP-L* & ultra- high purity & sintering & $>99.9999 \%$ & uniaxial forging \\
\hline W-UHP-S ** & ultra- high purity & sintering & $>99.9999 \%$ & uniaxial forging \\
\hline PIM W 50/50, 52\% & manufactured by KIT & PIM & standard purity & none \\
\hline PIM W 50/50, 50\% & manufactured by KIT & PIM & standard purity & none \\
\hline
\end{tabular}

Table 1: The table summarises the sample materials. * Grain elongation in length direction of the sample. ** Grain elongation perpendicular to the length direction of the sample.

\subsection{Loading conditions in GLADIS}

The neutral beam facility GLADIS operates with an $\mathrm{H}$, He or mixed $\mathrm{H} / \mathrm{He}$ beam and has the capability to apply heat fluxes $\leq 45 \mathrm{MW} \mathrm{m}^{-2}$ for $45 \mathrm{~s}$ pulse length [6]. The full width of the Gaussian beam at $80 \%$ central power density is $70 \mathrm{~mm}$. The orientation of the loaded surface is perpendicular to the beam axis. The surface temperature was recorded with pyrometers and with an IR camera; sample bulk temperatures were measured by thermocouples. A two-colour pyrometer was used in the temperature range between $550^{\circ} \mathrm{C}(823 \mathrm{~K})$ and $1700^{\circ} \mathrm{C}(1973 \mathrm{~K})$ to overcome the problem of emissivity changes of the loaded $\mathrm{W}$ surface. Temperatures up to $2200^{\circ} \mathrm{C}(2473 \mathrm{~K})$ were measured by a one-colour pyrometer. The mock-ups were water cooled with a velocity of $12 \mathrm{~m} / \mathrm{s}$, inlet temperature $\mathrm{T}_{\text {in }}=20^{\circ} \mathrm{C}(293 \mathrm{~K})$ and a static pressure of 10 bar.

All experiments were performed at $28 \mathrm{kV}$ acceleration voltage and $10 \mathrm{MW} \mathrm{m}^{-2}$ heat flux. In the case of pure $\mathrm{H}$ loading, the ion species distribution resulted in target loading with $22 \% \mathrm{H}$ atoms of full energy ( $\mathrm{E}=28 \mathrm{keV}$ ), $43 \%$ of $1 / 2 \mathrm{E}$ and $35 \%$ of $1 / 3 \mathrm{E}$. The mean particle energy is $15 \mathrm{keV}$. H $\alpha$ Doppler spectroscopy was used to determine the energy and species distribution of the incident particles. The applied particle ratio of the mixed $94 \mathrm{H} / 6 \mathrm{He}$ beam is based on the measured extraction current and the "source efficiency" of the ion source according to the method described in reference [7]. Only the Doppler shift from $\mathrm{He}^{+}$was spectroscopically identified for the He fraction. An $\mathrm{H}$ species distribution similar to that of pure $\mathrm{H}$ operation is assumed. 
The main experimental data including atom fluxes, exposure times and applied fluences are summarised in Table 2.

\begin{tabular}{|c|c|c|c|c|c|}
\hline Assessed samples & $\begin{array}{c}\text { Surface } \\
\text { temp. } \\
{ }^{\circ} \mathbf{C} / \mathbf{K}\end{array}$ & $\begin{array}{c}\text { No. of } \\
\text { pulses }\end{array}$ & $\begin{array}{c}\text { Loading } \\
\text { time } \\
\mathbf{S}\end{array}$ & $\begin{array}{c}\text { Incident } \\
\text { fluence } \\
\mathbf{\Phi}\left[\mathbf{m}^{-2}\right]\end{array}$ & $\begin{array}{c}\text { Physical } \\
\text { sputtering } \\
\boldsymbol{\mu m}\end{array}$ \\
\hline Hydrogen loading & & & & & \\
$15 \mathrm{~mm}$ sample height & $1500 / 1723$ & 85 & 2550 & $1.0 \mathrm{E}+25$ & 0.3 \\
$20 \mathrm{~mm}$ sample height & $2020 / 2293$ & 85 & 2550 & $1.0 \mathrm{E}+25$ & 0.3 \\
PIM W 50/50, 50\% & $1700 / 1973$ & 250 & 7500 & $3.0 \mathrm{E}+25$ & 0.9 \\
PIM W 50/50, 52\% & $1700 / 1973$ & 250 & 7500 & $3.0 \mathrm{E}+25$ & 0.9 \\
$\mathbf{9 4}$ H/ 6 He loading & & & & & \\
$15 \mathrm{~mm}$ sample height & $1500 / 1773$ & 104 & 3143 & $1.2 \mathrm{E}+25$ & 0.8 \\
20 mm sample height & $2020 / 2293$ & 104 & 3143 & $1.2 \mathrm{E}+25$ & 0.8 \\
\hline
\end{tabular}

Table 2: Summary of investigated samples and loading conditions. All tests were performed at $10 \mathrm{MW} \mathrm{m}^{-2}$ heat load and $30 \mathrm{~s}$ pulse length. Physical sputtering values are calculated according to the literature [17].

\section{Results and Discussion}

\subsection{Introductory remarks}

A general observation independent of the $\mathrm{W}$ grade or loading species (i.e. $\mathrm{H}$ or $\mathrm{H} / \mathrm{He}$ ) can be deduced when we compare our results to the electron beam loading experiments of He-cooled W-based divertor mock-ups described in reference [8]. In both experiments, the applied average heat flux was $10 \mathrm{MW} \mathrm{m}{ }^{-2}$ and heating pulses with a duration of 30 seconds were applied. Also, the total numbers of pulses were nearly identical: 89 pulses for module \#17 in reference [8] compared to 85 pulses in our experiments. The surface temperature of the electron beam loaded module $\# 17$ in ref [8] ranged from $1600^{\circ} \mathrm{C}(1873 \mathrm{~K})$ to $1700^{\circ} \mathrm{C}$ (1973 K) [9]. This temperature range is enclosed within the two temperatures covered by our experiments, i.e. $1500^{\circ} \mathrm{C}(1773 \mathrm{~K})$ and $2000^{\circ} \mathrm{C}(2273 \mathrm{~K})$.

Neglecting small differences in the surface temperatures, it must be concluded that the loading conditions listed above were identical for the two experiments, with the only difference being the particle species delivering the heating power and the fact that the electron beam loading is applied by a scanned beam, whereas the neutral beam provides a stationary and homogeneous loading. The evolution of the sample with pulse number, however, is completely different: Irrespective of the $\mathrm{W}$ grade and the loading particle species, none of our samples shows any near-surface modification ranging deeper than a few microns. We did not observe any cracks. Reference [8], however reports severe crack formation up to a depth of several hundred microns. 
The difference in the results of these experiments applying similar power loads and surface temperatures requires an explanation. One possibility would be the energy reflection of the samples with respect to the impinging particle species: For an $\mathrm{H}$ or He beam the reflected energy at normal incidence is in the range of a few percent [10]. For an electron beam of tens of $\mathrm{keV}$, however, nearly $50 \%$ of the incident power is reflected [11]. An existing crack running perpendicular to the surface may locally lead to the absorption of a substantially larger fraction of the incident power compared to a smooth surface, if electrons are multiply scattered by the crack walls until they are finally absorbed. This local overheating might lead to crack growth. The very high local heat flux during the beam scanning of the electron beam could even amplify this damage process.

In case of neutral beam loading with energetic $\mathrm{H}$ or $\mathrm{He}$ atoms, an existing surface crack, however, would change the local power absorption only marginally.

Therefore the strong crack growth reported in Ref. [8] might be due to a self-amplification mechanism inherent to the interaction of energetic electrons with W surfaces. Similar crack formation and growth with increasing pulse number was reported for electron beam testing of bulk $\mathrm{W}$ at 7-9 $\mathrm{MW} \mathrm{m}^{-2}$ in the literature, however with higher resulting peak surface temperatures and without active cooling [12].

\subsection{Thermally induced grain growth}

The mechanical properties of the material are related to the grain size distribution. Above the recrystallization threshold, the mechanical properties of heavily deformed $\mathrm{W}$ degrade significantly when grain growth occurs.

For the hydrogen-loaded samples the respective grain size distributions have been determined by measuring grain diameters from backscatter electron images of $1050 \mu \mathrm{m} \times 910 \mu \mathrm{m}$ field of view, ignoring possible small-angle grain boundaries. For both surface temperatures, $1500^{\circ} \mathrm{C}\left(1773\right.$ and $2000^{\circ} \mathrm{C}(2273 \mathrm{~K})$, a substantial grain growth was observed. The results are shown in Fig.1. The commercial material (W-PL) displayed a grain size of $60 \pm 20 \mu \mathrm{m}$ after the loading procedure to $1500^{\circ} \mathrm{C}(1773 \mathrm{~K})$ surface temperature. Comparing this with the value obtained from the corresponding $2000^{\circ} \mathrm{C}(2273 \mathrm{~K})$ sample, no further increase of the average grain size is observed. This behaviour is similar for the heavily deformed ultra-high purity tungsten (W-UHP) material. After testing at $1500^{\circ} \mathrm{C}(1773 \mathrm{~K})$, however, this material still shows a significant degree of elongation in the two different working directions of $75 \pm 30 \mu \mathrm{m}$ and $145 \pm 80 \mu \mathrm{m}$, respectively. This asymmetry has disappeared in the $2000^{\circ} \mathrm{C}(2273 \mathrm{~K})$ sample. The average grain size of the two different orientations is marked as W-UHP-average in Fig.1. It remains fairly constant at $105 \mu \mathrm{m}$. As shown in Fig. 2, the Ta-alloyed material developed the smallest grains after the HHF experiments, which can be attributed to the grain stabilizing effect typical for solid solutions. Again there is no significant difference between the mean values of $(25 \pm 10) \mu \mathrm{m}$ for the $1500^{\circ} \mathrm{C}(1773 \mathrm{~K})$ sample and $(30 \pm$ 10) $\mu \mathrm{m}$ for the $2000^{\circ} \mathrm{C}(2273 \mathrm{~K})$ sample.

All samples were completely recrystallized at $1500^{\circ} \mathrm{C}(1773 \mathrm{~K})$ and $2000^{\circ} \mathrm{C}(2273 \mathrm{~K})$ after less than $1 \mathrm{~h}$ loading at $10 \mathrm{MW} \mathrm{m}^{-2}$. There is a clear relation between the grain size after loading and the purity or alloying of the material. W-5\% Ta formed the smallest grains, whereas the ultra-high purity $\mathrm{W}$ formed 
large grains. Furthermore, there are practically no significantly different grain sizes between the different heavily deformed materials.

As shown in Fig.3, the loading of the PIM samples resulted in recrystallization and a strong grain growth after the applied $250 \mathrm{HHF}$ pulses. However, pores which are due to the preliminary and not optimized manufacturing process survived the $7500 \mathrm{~s}$ loading at $2000^{\circ} \mathrm{C}(2273 \mathrm{~K})$.

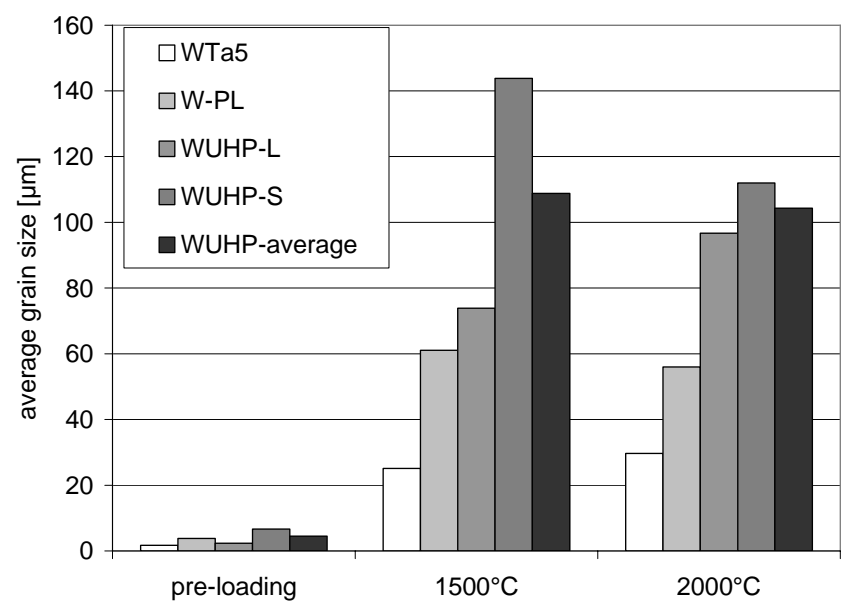

Fig. 1: Average grain size distribution after different loading temperatures.

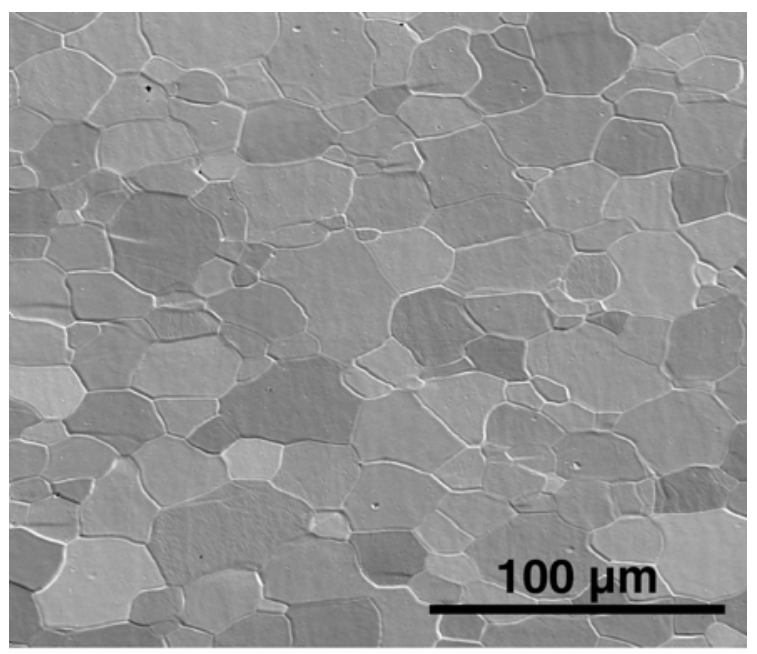

Fig 2: The surface of the WTa5 sample shows the smallest average grain size of the investigated materials after $\mathrm{H}$ loading at $2000^{\circ} \mathrm{C}(2273 \mathrm{~K})$.Grain growth and physical sputtering dominate the surface roughness. 


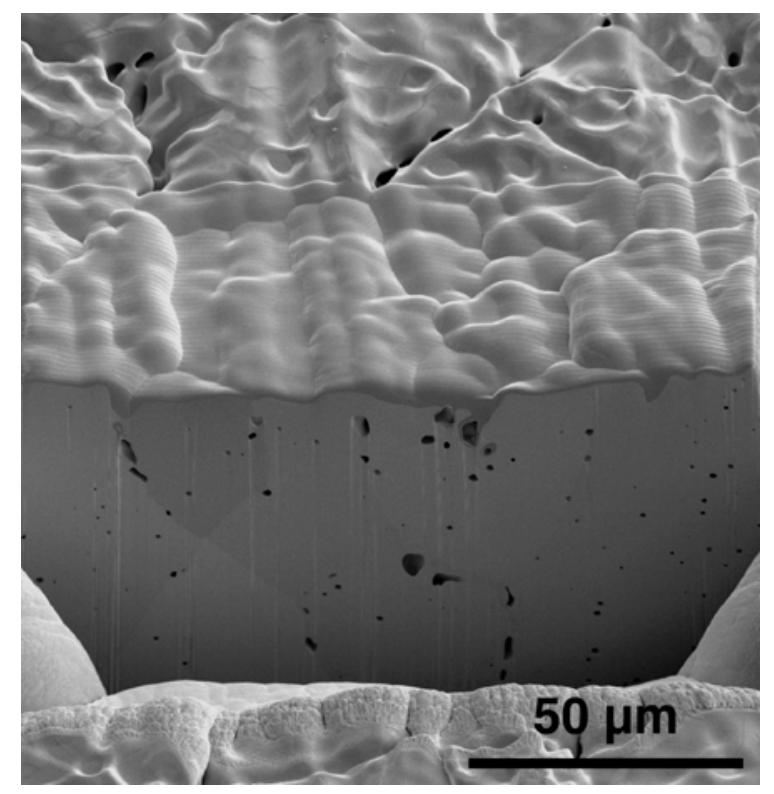

Fig. 3: SEM micrograph of the loaded surface of a PIM sample. The sample has been manufactured from a binary tungsten powder mixture of particle sizes of $1.7 \mu \mathrm{m}$ and $0.7 \mu \mathrm{m}$ and about 50-52 vol\% polymer binder system. Recrystallization and strong grain growth occurred during heat loading at $2000^{\circ} \mathrm{C}(2273 \mathrm{~K})$ surface temperature.

\subsection{Surface and near-surface modifications due to particle bombardment}

\subsubsection{Hydrogen loading}

For the hydrogen-loaded samples no blistering is observed. The only subsurface modifications found after the tests are a few small cavities with diameters in the $10 \mathrm{~nm}$ range at depths of around $200 \mathrm{~nm}$, i.e. around twice the average implantation depth. The $\mathrm{H}$ particle implantation depth between 40 and $110 \mathrm{~nm}$ for the above-mentioned energies is calculated according to the National Institute of Standards and Technology stopping power and range tables [13].

The surface modifications of the samples are dominated by grain growth after recrystallization and physical sputtering patterns.

We have never observed any thermally induced cracks growing into the bulk material, neither for the samples loaded to $1500^{\circ} \mathrm{C}(1773 \mathrm{~K})$ nor for the samples loaded to $2000^{\circ} \mathrm{C}(2273 \mathrm{~K})$.

\subsection{2. $94 \mathrm{H} / 6$ He loading}

The samples loaded with a $94 \mathrm{H} / 6 \mathrm{He}$ mixture show very significant changes of the surface and subsurface morphology. Qualitatively there is no significant difference between the samples loaded to $1500^{\circ} \mathrm{C}$ $(1773 \mathrm{~K})$ and those loaded to $2000^{\circ} \mathrm{C}(2273 \mathrm{~K})$. For both temperatures the surface morphology obtained 
after $94 \mathrm{H} / 6 \mathrm{He}$ loading resembles more the case of pure He loading than that of pure $\mathrm{H}$ loading. Images of He loaded $\mathrm{W}$ surfaces are given in reference [4].

In a combination of surface imaging and focussed-ion-beam (FIB) cross sectioning, Figure 4a shows the typical surface morphology after completion of the loading program: a smooth, wavy structure on the micron- scale together with submicron pores. As the cross-sectional part together with its magnification in Figure $4 \mathrm{~b}$ show, the pores visible on the surface are actually connected to an ensemble of cavities formed below the surface within a depth of about 200-500 $\mathrm{nm}$. The corresponding implantation depth of He atoms is about $70 \mathrm{~nm}$ and $40-110 \mathrm{~nm}$ for the $\mathrm{H}$ fraction of the beam. The description holds for both, $1500^{\circ} \mathrm{C}$ $(1773 \mathrm{~K})$ as well as $2000^{\circ} \mathrm{C}(2273 \mathrm{~K})$ loading.

As we are not reporting any gas desorption measurements in this manuscript, we cannot make a statement whether cavities are gas-filled bubbles or not. Therefore we use "cavity" in a general sense.

A quantitative analysis of the cavity size distribution reveals distinct differences for the two surface temperature regimes, as shown in Figure 5: With the class sizes employed, the $1500^{\circ} \mathrm{C}(1773 \mathrm{~K})$ data show a bimodal size distribution with two maxima: one below $50 \mathrm{~nm}$ and another around $150 \mathrm{~nm}$. In the $2000^{\circ} \mathrm{C}$ $(2273 \mathrm{~K})$ data there is a clear shift of the distribution to a larger number of smaller cavities and fewer larger cavities (The analysis shown in Figure 5 is based on magnifications that cannot obtain conclusive data on cavity sizes below 20-30 $\mathrm{nm}$.). Such an observation is contrary to what one would expect from pure annealing effects on He-implanted samples. In such a situation the so-called Ostwald ripening is expected to increase the fraction of larger cavities at the expense of the smaller ones upon temperature increase. This can be understood, when assuming a gas pressure in the bubbles that scales with the inverse bubble radius and is in thermodynamic equilibrium with the solute phase $[14,15]$. The fact that we observe the contrary behaviour here with respect to the surface temperature may be attributed to a number of reasons: In our cases, there is no simple annealing of a He population in W. Instead, there is a discontinuous flux of $\mathrm{H}$ and He particles impinging during the annealing time. Additionally, the sample surface is under compressive stress during the heat loading due to the thermal expansion of the hot surface. Ref. [14] points out that a stress field can be a cause for a bimodal size distribution under certain conditions. Finally, in the present case the samples are being loaded simultaneously with two different species of strongly differing mobilities and solubilities in $\mathrm{W}$ [16], i.e. $\mathrm{H}$ and $\mathrm{He}$, which might also be a cause for a bimodal structure of the cavity size distribution. 


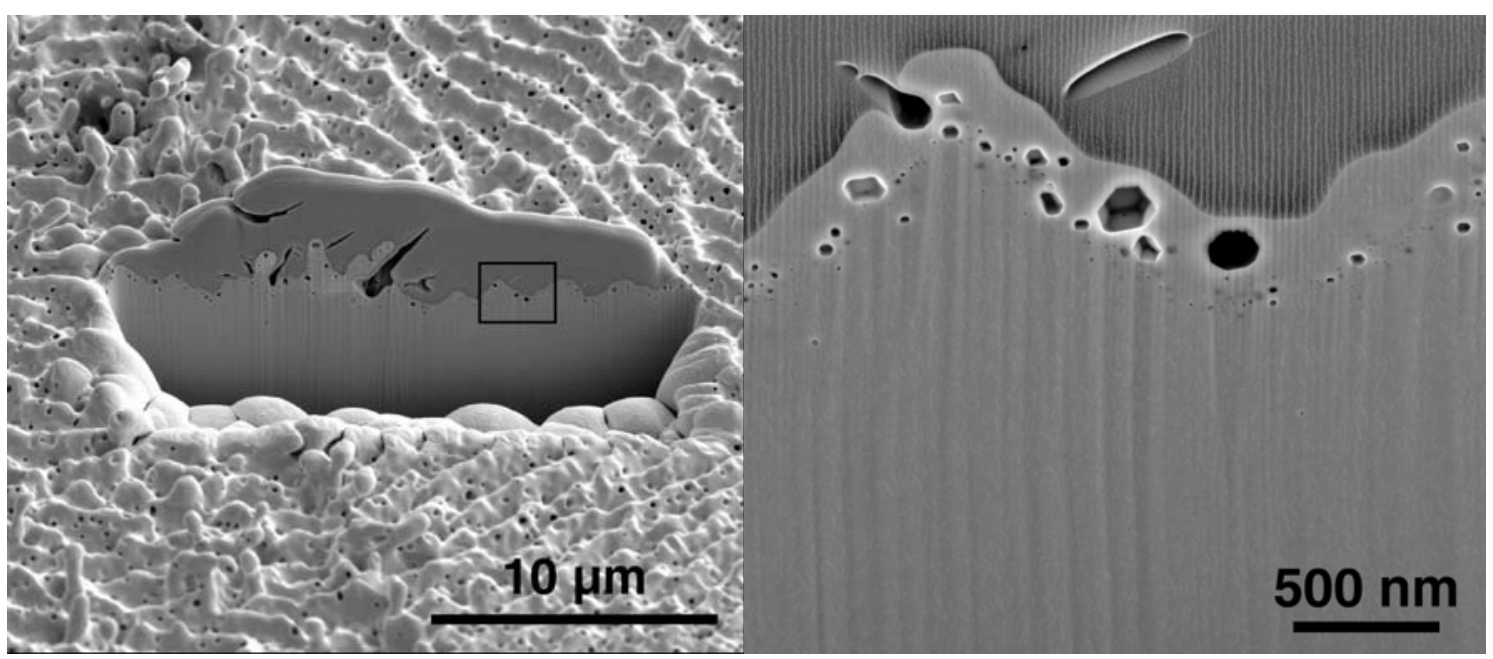

Fig. 4a (left): FIB cross-section and view on the surface of sample W-PL after mixed H/He loading at $2000^{\circ} \mathrm{C}(2273 \mathrm{~K})$. The dark grey coating layer in the centre of the image resulted from the FIB preparation process. The structure of the $W$ material is visible in light grey.

Fig. $4 b$ (right): Magnification of the IB cross-section of Fig. 4a. The two large pores in the dark grey top layer resulted from the preparation process.

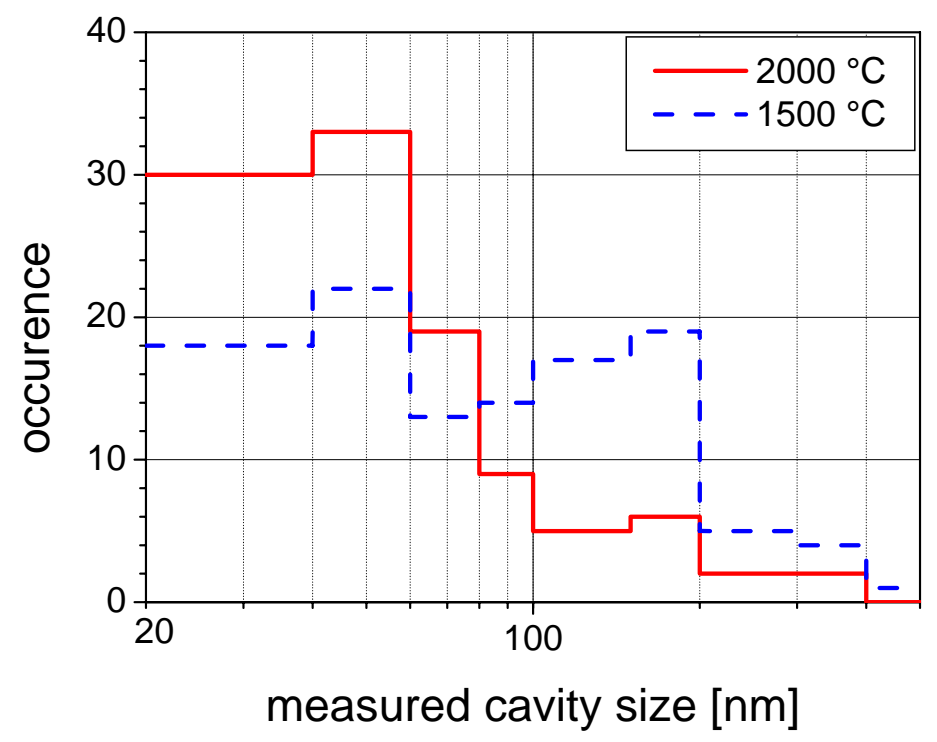

Fig. 5: Comparison of near- surface cavity size distribution after $94 \mathrm{H} / 6 \mathrm{He}$ loading at $10 \mathrm{MW} \mathrm{m}^{-2}$ for surface temperatures of $1500^{\circ} \mathrm{C}(1723 \mathrm{~K})$ and $2000^{\circ} \mathrm{C}(2273 \mathrm{~K})$, respectively.

\section{Summary and outlook}

High heat flux tests on four different types of W materials have been reported. In all cases substantial grain growth was observed after less than one hour at temperatures of $1500^{\circ} \mathrm{C}(1723 \mathrm{~K})$ and $2000^{\circ} \mathrm{C}(2273 \mathrm{~K})$ respectively. For the heavily deformed materials a preferential grain elongation disappeared at $2000^{\circ} \mathrm{C}$ (2273 K). 
For $\mathrm{H}$ loading no substantial change of the surface and near-surface morphology occurred. We therefore assume that the main erosion mechanism for loading with pure hydrogen is physical sputtering. For loading with a $94 \% / 6 \%$ mixture of $\mathrm{H}$ and $\mathrm{He}$, the He already seem to dominate the evolution of the surface morphology. Since a strong structuring of the near-surface region occurs in this case with a wavy structure containing a lot of cavities of various sizes, physical sputtering alone might not be the prevailing erosion mechanism here. A detailed study of the gross erosion rate under the various loading conditions, however, is still outstanding.

For all of the four materials investigated in this study, none of the applied loading conditions led to the development of cracks extending from the surface into the bulk of the material as was the case in electron beam HHF studies.

\section{Acknowledgement}

The authors would like to thank Thomas Koppitz from Research Centre Jülich and Luigi Spatafora from KIT for brazing the mock-ups.

\section{References:}

[1] M. Rieth, A. Hoffmann, Int. J. Refract. Met. Hard Mater. 28, 679 (2010)

[2] P. Norajitra et al., Nucl. Fusion 45 (2005) 1271-1276

[3] D. N.Hill, J. Nucl. Mater. 241-243 (1997) 182-198

[4] H. Greuner et al., J. Nucl. Mater. 417 (2011) 495-498

[5] S. Antusch et al., J. Nucl. Mater. 417 (2011) 533-535

[6] H. Greuner, et al., J. Nucl. Mat. 367-370, 1444-1448 (2007)

[7] H. D. Falter et al., Rev. Sci. Instrum. 71 (2000) 3723-3727

[8] G. Ritz et al., Fus. Eng. Des. 84 (2009) 1623-1627

[9] P. Norajitra et al., J. Nucl. Mater. 386-388 (2009) 813-818

[10] W. Eckstein, Max-Planck-Institut für Plasmaphysik, 2009, Report IPP 17/12

[11] A. Schmidt et al., Phys. Scr. T138 (2009) 014034

[12] T. Hirai et al., Phys. Scr. T128 (2007) 144

[13] M. J. Berger, Stopping-Power and Range Tables for Electrons, Protons, and Helium Ions, http://www.nist.gov/pml/data/star/index.cfm

[14] J. Rothaut et al., Phil. Mag. A 47 (1983) 781

[15] G. W. Greenwood and A. Boltax, J. Nucl. Mater. 5 (1962) 234

[16] K.O.E. Henriksson et al., Fus. Sci. Technol. 50 (2006) 43

[17] R. Behrisch, W. Eckstein (Eds.), Sputtering by Particle Bombardment, Springer Berlin 2007; Topics in Applied Physics 110 